Disclosure of Interest: A. Lila: None declared, L. Denisov: None declared, T. Plaksina: None declared, S. Smakotina: None declared, E. Kunder: None declared, N. Soroka: None declared, A. Kastanayan: None declared, O. Nes meyanova: None declared, O. Antipova: None declared, E. Ilivanova: None declared, A. Eremeeva Employee of: JSC BIOCAD, E. Dokukina Employee of: JSC BIOCAD, E. Chernyaeva Employee of: JSC BIOCAD, R. Ivanov Employee of: JSC BIOCAD

DOI: 10.1136/annrheumdis-2018-eular.2332

\section{THU0194 CD4+ T CELLS, IMMUNOGLOBULINS AND RISK OF INFECTION IN PATIENTS WITH RHEUMATOID ARTHRITIS OVER MULTIPLE CYCLES OF RITUXIMAB}

F. Martins ${ }^{1}$, A. Bensalem ${ }^{2}$, T. Bejan-Angoulvant ${ }^{2,3}$, A. Lhommas ${ }^{1}$, J. Mélet $^{1,2}$, S. Mammou ${ }^{1}$, G. Thibault ${ }^{2,4,5}$, L. Bernard ${ }^{6}$, P. Goupille ${ }^{1,2}$, D. Mulleman ${ }^{1,2}$. ${ }^{1}$ Rheumatology, CHRU de Tours; ${ }^{2}$ EA GICC, University of Tours; ${ }^{3}$ Clinical Pharmacology, CHRU de Tours; ${ }^{4}$ CNRS ERL 7001, University of Tours; ${ }^{5}$ Immunology, ${ }^{6}$ Infectious diseases, CHRU de Tours, Tours, France

Background: Rituximab (RTX) may be responsible for infectious event in RA patients. Immunological markers may be associated with the occurrence of infections.

Objectives: To evaluate lymphocyte counts and immunoglobulin concentrations over multiple cycles of RTX in RA patients, and to analyse the relationship between these markers and the occurrence of infections.

Methods: Retrospective monocentric study on 94 RA patients treated with RTX At baseline and during follow up, lymphocyte phenotyping (CD4+, CD3+, CD19 +cells), gammaglobulin, IgG, IgM and IgA concentration were assessed Patients were dichotomized according to the absence or presence of infectious events. A student's test was used to compare the continuous variables and a Chi2 test or the Fisher test was used for the dichotomous variables.

Results: A total of 119 infectious events occurred during follow-up, of which only 11 were serious, with respective incidences of 65 per 100 patient-years and 6 per 100 patient-years. Low IgM concentration at RTX initiation and low IgG concentration $(<5 \mathrm{~g} / \mathrm{L})$ throughout follow-up were associated with an increased risk of infection. Both gammaglobulin and IgG concentrations decreased along with successive cycles of RTX in patients with infection, while they remained stable in patients without infection. Twelve patients had a CD4 +cell count $<200 / \mathrm{mm}^{3}$ during follow up, of which one with a CD4 +cell count $233 / \mathrm{mm}^{3}$ at baseline, who subsequently presented an opportunistic infection.

Conclusions: Gammaglobulin, IgM and IgG concentrations and CD4 +cell count are valuable before RTX initiation in RA patients. IgG or gammaglobulin concentration should also be monitored before each cycle. CD4 +lymphocytes monitoring should be considered in patients with low value at initiation.

Disclosure of Interest: F. Martins: None declared, A. Bensalem: None declared, T. Bejan-Angoulvant: None declared, A. Lhommas: None declared, J. Mélet: None declared, S. Mammou: None declared, G. Thibault: None declared, L. Bernard: None declared, P. Goupille Consultant for: Abbvie, Biogaran, BMS, Hospira Janssen-Cilag, MSD, Pfizer, Sanofi-Genzyme and UCB, D. Mulleman Grant/ research support from: Abbvie and Nordic Pharma, Consultant for: MSD, Novartis, UCB and Pfizer

DOI: 10.1136/annrheumdis-2018-eular.7030

\section{THU0195 \\ PREVALENCE OF OCCULT HEPATITIS B CARRIER STATUS AND ITS ASSOCIATED FACTORS IN PATIENTS WITH RHEUMATIC DISEASES UNDERGOING BIOLOGICAL THERAPIES}

C.C. Mok ${ }^{1}$, L.Y. Ho ${ }^{1}$, K.L. Chan ${ }^{1}$, S.M. Tse ${ }^{1}$, C.H. To ${ }^{2} .{ }^{1}$ Medicine, Tuen Mun Hospital; ${ }^{2}$ Medicine, Pok Oi Hospital, HK, Hong Kong

Objectives: To study the prevalence of occult hepatitis B carrier status and its associated factors in patients with rheumatic diseases undergoing biological therapies

Methods: Consecutive adult patients with various rheumatic diseases who were currently receiving biological therapies between November 2016 and April 2017 were recruited in this cross-sectional study. Blood was taken for evidence of hepatitis B infection ( $\mathrm{HBsAg}$, anti-HBs, anti-HBc-lgG). For patients tested positive for $\mathrm{HBsAg}$ or anti-HBc-lgG, assay of serum HBV-DNA level was also performed. Occult hepatitis $B$ carrier was defined as patients who were $\mathrm{HBs} A g$ negative but anti-HBc-lgG positive. Logistic regression was performed to study factors independently associated with occult hepatitis $B$ carrier status in these patients.

Results: 310 Chinese patients were studied $(60 \%$ women, age at biological therapy $44.0 \pm 13.0$ years). The underlying rheumatic diseases requiring biological therapies were rheumatoid arthritis $(46 \%)$, spondyloarthritis $(31 \%)$, psoriatic arthritis (12\%) and systemic lupus erythematosus (8.1\%). The biologics being used were the TNF inhibitors $(66 \%)$, tocilizumab $(16 \%)$, abatacept $(2.9 \%)$, rituximab $(7.7 \%)$, belimumab (5.8\%) and tofactinib (1.3\%). Hepatitis B carrier (HBsAg +) status was detected in $11(3.5 \%)$ patients and they were all put on preemptive anti-viral therapy (entecavir). A total of 105 patients (34\%) were occult hepatitis $B$ carriers (HBsAg- but anti-HBc-lgG+). Anti-HBs was present in 83/105 (79\%) of these patients. Occult hepatitis $B$ carriers were significantly older than the non carriers ( $49.9 \pm 11.1$ vs $40.9 \pm 13.3$ years; $p<0.001)$, and were more frequently identified in rheumatoid arthritis than other rheumatic diseases $(45 \%$ vs $25 \%$; $\mathrm{p}<0.001)$. However, there was no gender difference in the prevalence of the occult hepatitis $B$ carrier status ( $37 \%$ in women vs $28 \%$ in men; $p=0.10$ ). Logistic regression revealed that older age (RR 1.05 [1.03-1.08] per year; $p<0.001)$ was the only independent factor significantly associated with occult hepatitis B infection. Rheumatoid arthritis was not significantly associated with occult hepatitis B carrier status after adjustment for age and sex. Of the occult hepatitis B carriers, $9(8.6 \%)$ had detectable HBV-DNA levels but all were very low titers $(<100 \mathrm{lU} / \mathrm{ml})$. Five (56\%) patients with detectable HBV-DNA levels received entecavir treatment during biological therapies, while $19(20 \%)$ patients without detectable HBV-DNA were put on preemptive entecavir treatment (including all patients who were receiving rituximab). None of the overt $(\mathrm{HBsAg}+)$ or occult hepatitis $\mathrm{B}(\mathrm{HBsAg}$ anti-HBc-lgG+) carrier patients developed clinical reactivation of hepatitis $B$ during a mean of $5.0 \pm 3.7$ years of biological therapies.

Conclusions: Occult hepatitis B carrier status was present in one-third of Hong Kong Chinese patients with various rheumatic diseases undergoing biological therapies. Older age was the only independent factor associated with occult hepatitis $B$ infection. Despite the relatively low rate of preemptive anti-viral treatment in these patients, clinical reactivation of hepatitis B was not reported over 5 years of biological therapies.

Disclosure of Interest: None declared

DOI: 10.1136/annrheumdis-2018-eular.4333

\section{THU0196 \\ DO CONTEXTUAL FACTORS INFLUENCE SURVIVAL ONDRUG OF BIOSIMILARS IN CLINICAL PRACTICE?}

D. Di Giuseppe ${ }^{1}$, T. Frisell ${ }^{2}$, E. Lindqvist ${ }^{3}$, L. Jacobsson ${ }^{4}$, C. Turesson ${ }^{3}$, C. Sjöwall ${ }^{5}$, J. Askling ${ }^{1}$, on behalf of ARTIS group. ${ }^{1}$ Department of MedicineSolna, Karolinska Institutet, ${ }^{2}$ Department of MedicineSolna, SRQ, Stockholm; ${ }^{3}$ Lund University and Skåne University Hospital, Malmö; ${ }^{4}$ Sahlgrenska Academy, University of Gothenburg, Gothenburg; ${ }^{5}$ Linköping University, Linköping, Sweden

Background: The introduction of biosimilars has been linked to concerns regarding their effectiveness and safety compared to their originator products. Whilst randomized controlled trials may address their relative efficacy, the outcome of biosimilars in clinical practice may be influenced by contextual factors, such as the treating rheumatology unit's experience with biosimilars and non-medical switching.

Objectives: To analyze whether contextual factors, such as department size and use of biosimilars, and calendar period of treatment start, influence time until treatment discontinuation (i.e. drugsurvival) of biosimilars as compared to corresponding originator products.

Methods: We used data from the Swedish Rheumatology Quality register to identify all patients with rheumatoidarthritis, ankylosing spondylitis, psoriatic arthritis, or other spondyloarthropathies who started infliximab between March 1st 2015 and Sept 30th 2017 or etanercept between April 1st 2016 and Sept 30th 2017, as their firstever biologic. Kaplan-Meier curves and Cox models were used to assess the association between drug survival and the size of the rheumatology unit, itsuse of biosimilars (extent of biosimilar use above/below national median a teach time point), and whether the treatment start occurred soon after biosimilar introduction (infliximab: first 12 months, etanercept: 6 months counting from first date of availability of the biosimilar in question). To avoid artefacts, patients were censored if switching from the originator to a biosimilar (or vice versa).

Results: During the study period, 368 and 738 patients started infliximab originator or biosimilar, and 125 and 2079 started etanercept originator or biosimilar, as first ever biological treatment. Overall, the hazard ratio $(\mathrm{HR})$ of discontinuing treatment (comparing the biosimilar vs its originator) was 1.21 (95\% Cl: $0.96-1.51)$ for infliximab and 0.88 (95\% Cl: $0.57-1.35)$ for etanercept, adjusted for indication age(quartiles), gender, region, and HAQ (quartiles), DAS28 (quartiles) and globalhealth (quartiles) at treatment start. Patients treated in large clinics (more than 1695 patients (75th percentile) at the end of the study period) were at a lower risk of drug discontinuation (table 1). We noted no association between overall biosimilar use in the rheumatology clinic in question and survival on drug (neither originator nor biosimilar). By contrast, those who started infliximab biosimilar later had a lower risk of discontinuing (HR: 0.65 (95\% Cl:0.50-0.85)) compared to those who started in the first year of availability. For etanercept biosimilar, no such association was noted. 